\title{
Synthesis, Growth and Characterization of Nonlinear Optical Single Crystal of Serine Succinate
}

\author{
S. Akilandeswari ${ }^{1,2}$, L. Jothi ${ }^{{ }^{*}}$ \\ ${ }^{1}$ Department of Physics, Namakkal Kavignar Ramalingam Government Arts College for Women, Namakkal, India \\ ${ }^{2}$ Periyar University, Salem, Tamilnadu, India \\ Email: *jothilakshmanan@gmail.com
}

How to cite this paper: Akilandeswari, S. and Jothi, L. (2021) Synthesis, Growth and Characterization of Nonlinear Optical Single Crystal of Serine Succinate. Journal of Minerals and Materials Characterization and Engineering, 9, 75-89.

https://doi.org/10.4236/jmmce.2021.91006

Received: November 26, 2020

Accepted: January 25, 2021

Published: January 28, 2021

Copyright $\odot 2021$ by author(s) and Scientific Research Publishing Inc. This work is licensed under the Creative Commons Attribution International License (CC BY 4.0).

http://creativecommons.org/licenses/by/4.0/

\section{(c) (i) Open Access}

\begin{abstract}
Nonlinear optical single crystal of Serine Succinate (SSA) was grown from a mixed solvent of water, ethanol and methanol. Since amino acid exhibits nonlinear optical property, it is of interest to dope them in serine. The overwhelming success of molecular engineering in controlling nonlinear optical properties in last decade has prompted better initiative in crystal engineering. In the present study single crystals of serine doped with succinic acid in different ratios have been grown by slow evaporation solution growth method. Grown serine succinate crystals were subjected to various characterization techniques. The cell parameters of the grown crystals were characterized by $\mathrm{X}$-ray diffraction analysis. FT-Raman spectral studies were carried out on the SAA grown material to confirm the synthesized compound and the functional groups of serine succinate single crystal were identified from FTIR analysis. The optical transparency and upper cut off value of UV transmission spectrum of SSA crystal were recorded. Fluorescence study was also carried out for the grown materials. The mechanical hardness was estimated by Vickers's micro hardness tester. The second harmonic generation (SHG) of the grown crystal was confirmed by Kurtz powder technique. Thermal properties of serine succinate crystal were evaluated with thermogravimetric, differential thermal and differential scanning calorimetric analyses. The SEM studies were also reported.
\end{abstract}

\section{Keywords}

Crystal Growth, Slow Evaporation Technique, Thermo Gravimetric Analysis

\section{Introduction}

Nonlinear optical materials generating second harmonic frequency have a sig- 
nificant impact on laser technology, optical communication and optical storage technology. Nonlinear optics is the study of interaction of radiation with matter in which certain variables describing the response of matter are not proportional to the variables describing the radiation. Nonlinear optical materials play a major role in the technology of photonics. In all materials, nonlinear effects of various types are observed at sufficiently high intensities. Frequency doubling is one of the visually dramatic features among the nonlinear optical processes [1]. Recently semi-organic crystals have been proposed as new candidates with interesting nonlinear optical properties as they possess high thermal and mechanical stability compared to organics [2] [3]. Crystallization of organic materials for use in nonlinear optical devices is of great interest due to their high nonlinearity, high flexibility in terms of molecular structure, high optical damage threshold and low cost [4]. In many organic nonlinear optical materials there is a solid frame work of conjugated $\pi$ electrons along with weak Vander Waals and hydrogen bonds which are responsible for most of their nonlinear optical properties. Metal complexes like organic compounds have several advantages as far as their third-order nonlinear optical properties are concerned [5].

Organic materials are difficult to grow as large size optical quality crystals for device applications [6]. Combined organic and inorganic, named semi-organic, can be grown easily by solution growth technique [7]. Semi-organic materials gain importance over inorganic materials, because of their large polarizability, wide transmission, and high laser damage threshold [8]. Semi-organic materials have the potential for combining the high optical nonlinearity and chemical flexibility of inorganic material [9]. Only non-centrosymmetric alignment of the chromophores in the crystal lattice leads to an observable bulk second-order nonlinear response [10]. In order to obtain the adjustment of the nonlinear efficiency, based on the molecular engineering and crystal engineering approach, it is tried to develop a new method to design organic nonlinear optical second harmonic generation materials such as organic inclusion complex [11]. In this study, the crystal growth of serine succinate by slow evaporation technique and its characterization along with its optical properties are reported.

\section{Experimental Description}

Solution method with slow evaporation technique was adopted to grow the single crystals of the synthesized salt of serine and succinic acid with three different solvents namely ethanol, methanol and water. Serine and succinic acid were taken in the stoichiometric ratio 1:2 in ethanol and the mixture (SSAE) is stirred for 3 hour. The same procedure was adopted by taking serine and succinic acid in methanol (SSAM), serine and succinic acid in ethanol-methanol (SSAEM) and serine and succinic acid in ethanol-water (SSAEW) in the ratio 1:2. The mixture materials were stirred for 3 hours using magnetic stirrer at room temperature $\left(31^{\circ} \mathrm{C}\right)$. Then the solutions were filtered in beakers to remove the dust particles. The beakers were kept safely for the growth of crystals. The crystal growth phenomena were observed in each case. After two days, small crystals of 
serine succinate were appeared. Among the three solvents used to grow crystals, mixture materials stirred in the combination of serine, succinic acid and ethanol are grown as good quality transparent crystals. Crystals of suitable dimensions required for various characterization techniques were allowed to grow and harvested in two weeks. Photograph of such grown crystal is shown in Figure 1. The following reaction shows the formation of SSA crystals.<smiles>C[13CH](O)C(O)CC(=O)O</smiles>

\section{Results and Discussion}

\subsection{Single Crystal XRD}

Single crystal X-ray diffraction data for SSAE was recorded by using BRUKERNONIUS KAPPA APEX II CCD diffractometer system using Mo $\mathrm{K}_{\alpha}$ graphite monochromatic radiation. It is observed from the X-ray diffraction data that the grown crystal is monoclinic and the space group is $\mathrm{P}$. The lattice parameters have been determined as: $\mathrm{a}=5.07 \AA, \mathrm{b}=8.81 \AA, \mathrm{c}=5.50 \AA, \alpha=90.00^{\circ}, \beta=$ $91.06^{\circ}, \gamma=90.00^{\circ}$ and the volume of the unit cell is found to be $\mathrm{V}=246 \AA^{3}$.

\subsection{FTIR Spectral Analysis}

Fourier transform infrared spectroscopic studies were carried out in the region $400 \mathrm{~cm}^{-1}-4000 \mathrm{~cm}^{-1}$, it is recorded on Perkin Elmer FTIR spectrophotometer using $\mathrm{KBr}$ pellet technique [12]. The recorded spectra for SSAE, SSAM, SSAEM and SSAEW are shown in Figures 2(a)-(d).

In Figure 2(a) SSAE displays the aliphatic C-H symmetric stretching as a band at $2933 \mathrm{~cm}^{-1}$ [13]. The C-H symmetric in plane bend occurs at $1418 \mathrm{~cm}^{-1}$. The peak at $1177 \mathrm{~cm}^{-1}$ is due to $\mathrm{C}-\mathrm{C}$ skeletal vibration. The $\mathrm{C}-\mathrm{H}$ deformation vibration appears at $896 \mathrm{~cm}^{-1}$.

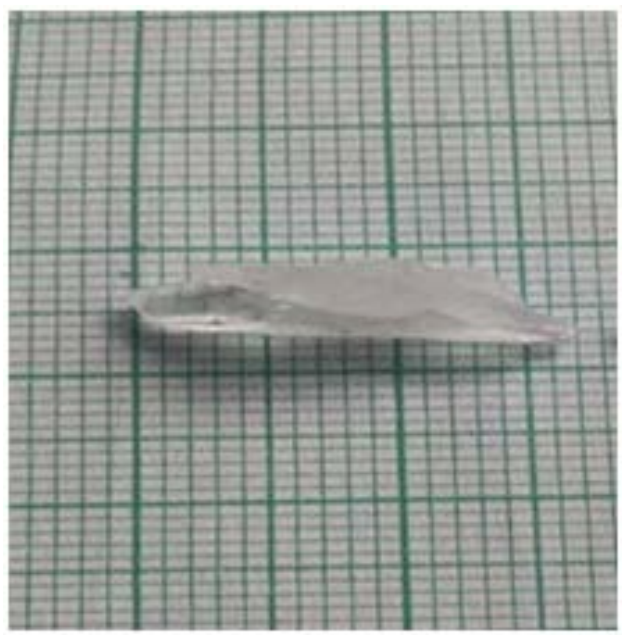

Figure 1. Photograph of SSA crystal. 


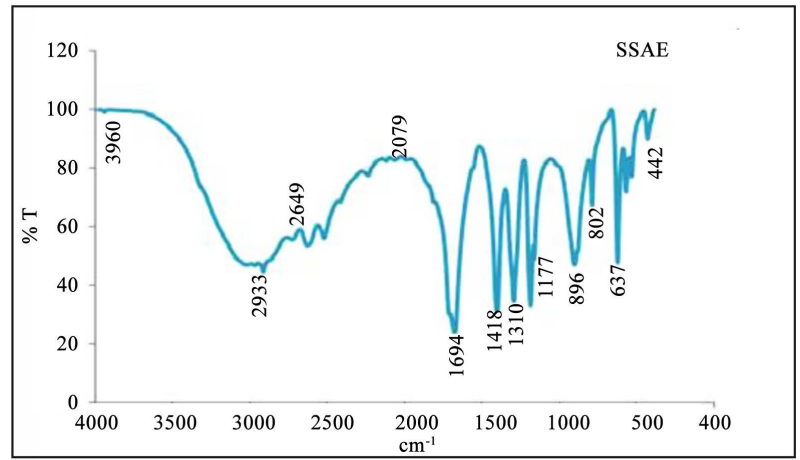

(a)

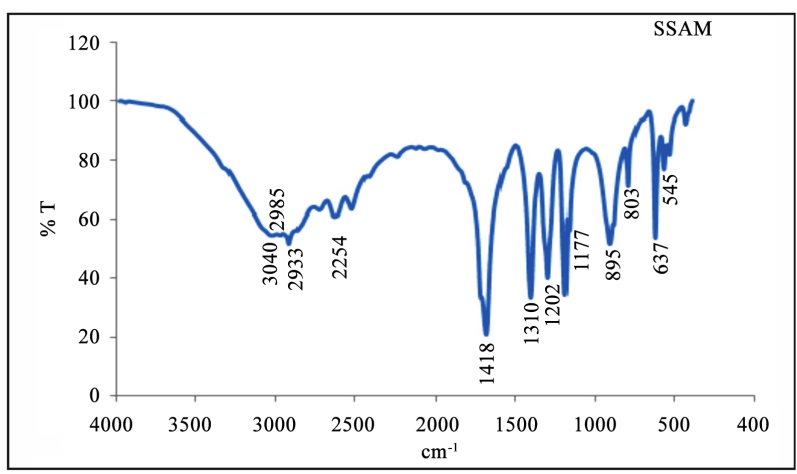

(b)

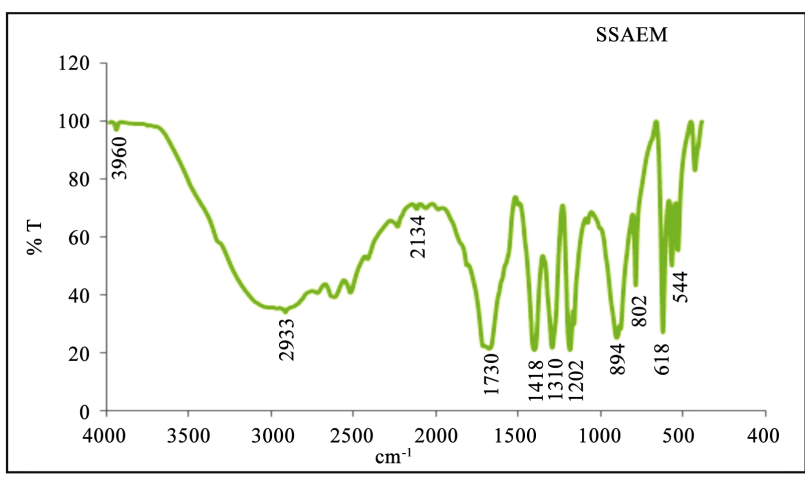

(c)

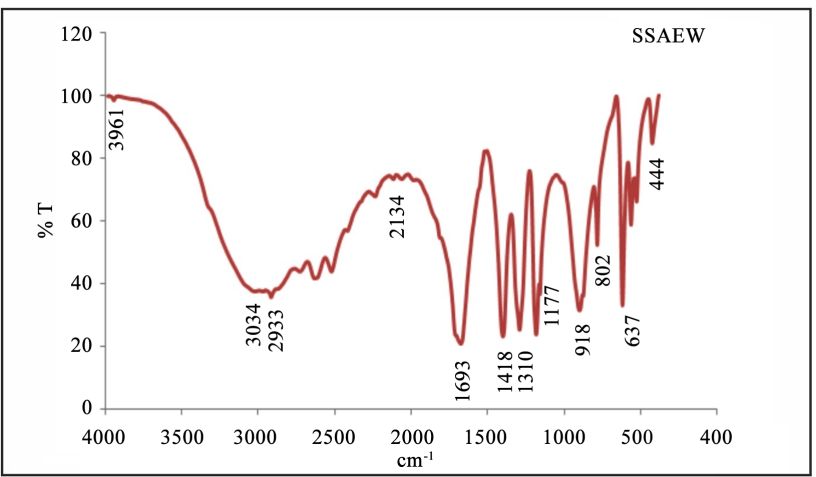

(d)

Figure 2. (a) FTIR spectrum of SSA in solvent-Ethanol; (b) FTIR spectrum of SSA in solvent-Methanol; (c) FTIR spectrum of SSA in solvent mixture of ethanol and methanol; (d) FTIR spectrum of SSA in solvent mixture of ethanol and water. 
In Figure 2(b) SSAM displays the aliphatic C-H symmetric stretching at 2933 $\mathrm{cm}^{-1}$. The symmetric stretching mode of $\mathrm{C}-\mathrm{H}$ in plane bend group appears at $1418 \mathrm{~cm}^{-1}$. The absorption peak at $1177 \mathrm{~cm}^{-1}$ corresponds to C-C stretching vibration. The bending mode of $\mathrm{C}-\mathrm{H}$ vibration occurs at $895 \mathrm{~cm}^{-1}$.

In Figure 2(c) SSAEM displays the symmetry stretching vibration of $\mathrm{CH}_{2}$ group at $2933 \mathrm{~cm}^{-1}$. The peak at $1418 \mathrm{~cm}^{-1}$ is assigned to symmetrical $\mathrm{COO}^{-}$ion group stretching. The peak appears at $1202 \mathrm{~cm}^{-1}$ is due to C-C skeletal vibration. The clusters of peaks below $1000 \mathrm{~cm}^{-1}$ are due to $\mathrm{C}-\mathrm{H}$ bending. A well-defined peak observed at $894 \mathrm{~cm}^{-1}$ and other sharp peaks identified in the low wave number regions are due to the bending vibration mode of $\mathrm{C}-\mathrm{H}$ bend.

In Figure 2(d) SSAEW displays the broad peak at $2933 \mathrm{~cm}^{-1}$ corresponds to $\mathrm{C}-\mathrm{H}$ stretching vibrations. Skeletal vibrations observed at $1418 \mathrm{~cm}^{-1}$ are due to in plane bending modes of $\mathrm{C}-\mathrm{H}$ bonds. The peak at $1177 \mathrm{~cm}^{-1}$ is due to $\mathrm{C}-\mathrm{C}$ stretching vibration. The peak at $895 \mathrm{~cm}^{-1}$ is attributed to $\mathrm{C}-\mathrm{H}$ deformation vibration [14]. The comparison of FTIR spectral assignments for various solvents is shown in Table 1.

\subsection{UV-VIS-NIR Spectral Analysis}

The optical transmission spectrum of serine succinate crystal was recorded Perkin Elmer Lamda 35 spectrophotometer in the wavelength range of $1100 \mathrm{~nm}$ $200 \mathrm{~nm}$. The obtained transmission spectrum of SSAE, SSAM, SSAEM and SSAEW are shown in Figure 3. In SSAE transmittance between $200-1100 \mathrm{~nm}$ is approximately $100 \%$ and the upper cut off wavelength is found at $300 \mathrm{~nm}$. In SSAM transmittance between $200 \mathrm{~nm}-1100 \mathrm{~nm}$ is approximately $97 \%$ and the upper cut off wave length is found at $250 \mathrm{~nm}$. In SSAEM transmittance between $200 \mathrm{~nm}-1100 \mathrm{~nm}$ is approximately $99 \%$ and the upper cut off wavelength is found at $240 \mathrm{~nm}$.

In SSAEW transmittance between $200 \mathrm{~nm}-1100 \mathrm{~nm}$ is approximately 95\% and the upper cut off wavelength is found at $250 \mathrm{~nm}$. The absence of absorption in the visible region confirms to the colourless nature of the crystal and is an advantage as it is the key requirement for materials having NLO properties [15]. The comparison of transmission of SSAE, SSAM, SSAEM and SSAEW is shown in Table 2. Serine, succinic acid and ethanol mixture (SSAE) has high percentage of transmittance (100\%) compared to the mixture of methanol, mixture of ethanol-methanol and mixture of ethanol-water.

Table 1. Comparison of FTIR spectral assignments.

\begin{tabular}{ccccc}
\hline & \multicolumn{4}{c}{ Vibrational frequency $\left(\mathrm{cm}^{-1}\right)$} \\
\hline SSAE & SSAM & SSAEM & SSAEW & Bond Assignment \\
\hline 2933 & 2933 & 2933 & 2933 & C-H Symmetric Stretch \\
1418 & 1418 & 1418 & 1418 & C-H in Plane Bend \\
1177 & 1177 & 1202 & 1177 & C-C Stretching Vibration \\
896 & 895 & 894 & 895 & C-H Out of Plane Bend \\
\hline
\end{tabular}



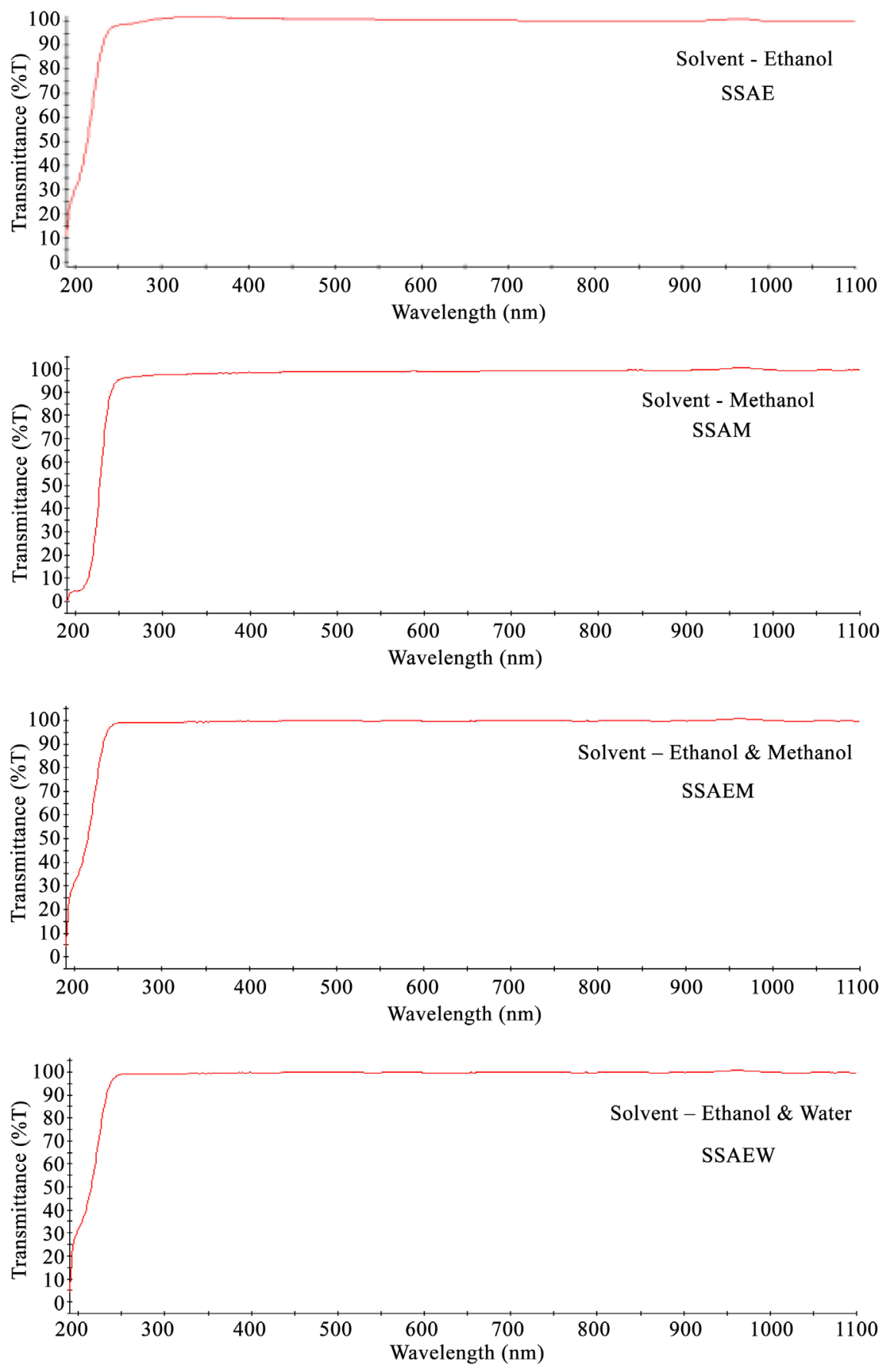

Figure 3. UV transmission spectrum of SSA.

Table 2. Comparison of UV-VIS-NIR studies.

\begin{tabular}{ccc}
\hline Solvent & Cut off Wavelength (nm) & Transmittance (\%) \\
\hline Ethanol & 300 & 100 \\
Methanol & 250 & 97 \\
Ethanol and Methanol & 240 & 99 \\
Ethanol and Water & 250 & 95 \\
\hline
\end{tabular}




\subsection{Fluorescence Study}

Fluorescence generally found in compounds containing aromatic functional groups with low energy $\Pi \rightarrow \Pi^{+}$transition levels. Compounds of aliphatic and alicyclic carbonyl structures are highly conjugated double bond structures exhibit fluorescence. The emission spectrum of SSA was recorded using HeliumNeon laser as the excitation source and JOBINVYON FLUROLOG 3 Spectrofluorometer in the range $250-600 \mathrm{~nm}$. The Fluorescence spectrum of SSA is given in Figure 4.

The fluorescence spectrum shows a peak at about $465.87 \mathrm{~nm}$ which indicates that the SSA crystal has a blue fluorescence emission [16] [17].

\subsection{Mechanical Studies}

The permanent deformation can be achieved by indentation, bending, scratching or cutting. The Vicker's hardness number $\left(H_{v}\right)$ was calculated using the formula,

$$
H_{v}=\frac{1.8544 P}{d^{2}}\left(\mathrm{~kg} / \mathrm{mm}^{2}\right)
$$

where,

$H_{v}$ is the Vicker's hardness number in $\mathrm{kg} / \mathrm{mm}^{2}$.

$P$ is the applied load in $\mathrm{kg}$.

$d$ is the diagonal length of the impression in $\mathrm{mm}$.

The variation of $H_{v}$ with load is given in Figure 5 and plot of $\log P$ versus $\log d$ is shown in Figure 6. It is evident from the Figure 5 that $H_{V}$ increases with increase in load upto $100 \mathrm{~g}$ and further increase in load causes cracks formation which leads the decrease in hardness value.

The relation between $P$ and $d$ is represented by Meyer's law $P=A d^{n}$.

$$
\log P=\log A+n \log d
$$

where $A$ is standard hardness and $n$ is constant. The Meyer's index number " $n$ "

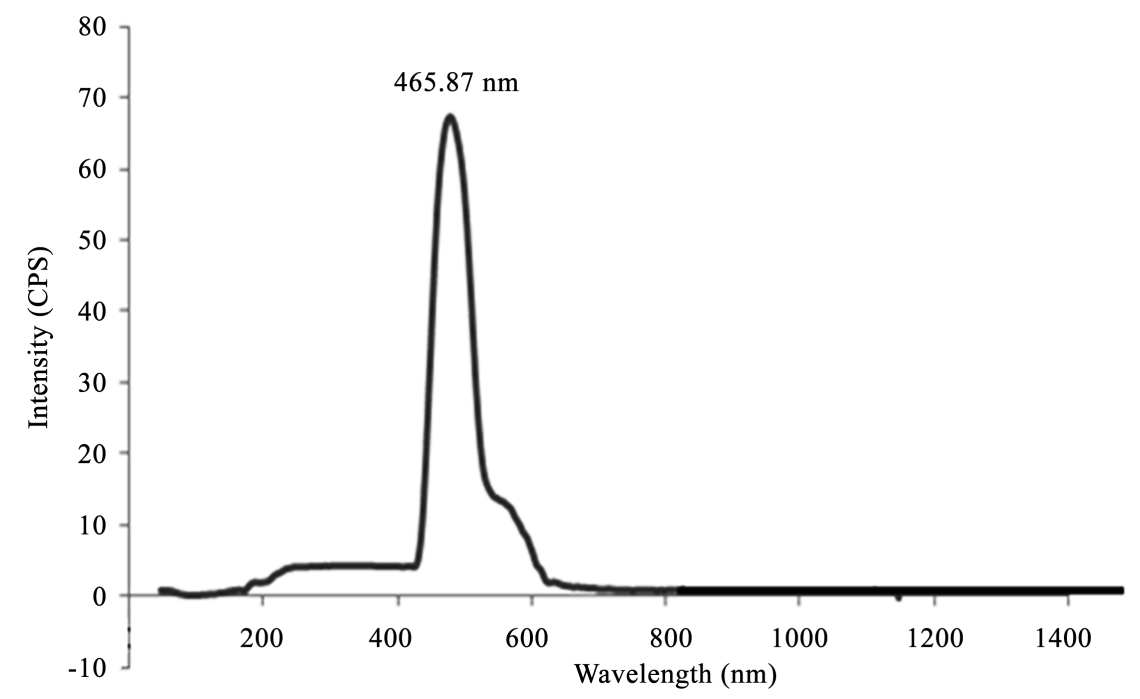

Figure 4. Fluorescence spectrum of SSA. 


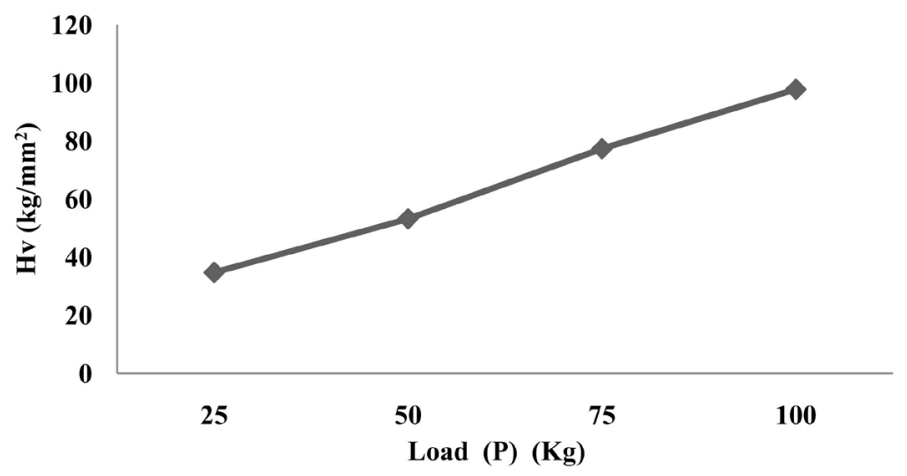

Figure 5. Hardness versus load for SSA.

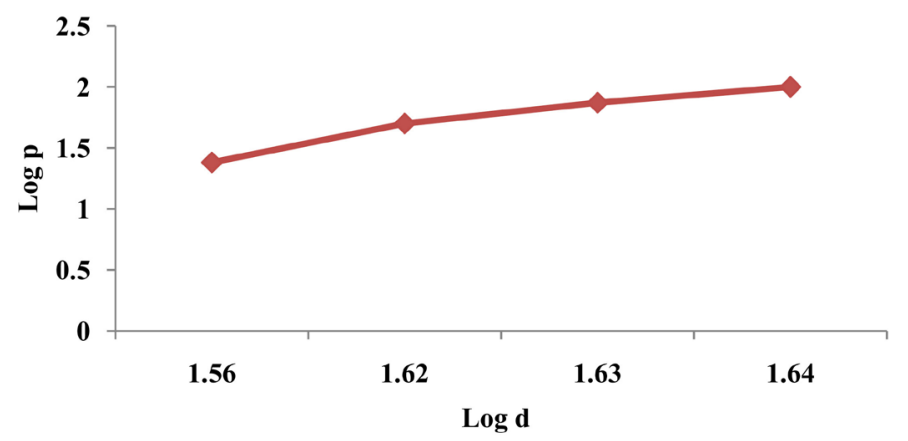

Figure 6. Graph between $\log P$ and $\log d$.

determined for SSA crystal is 3.2. According to Onitsch [18] and Hanneman [19] [20] " $n$ " should be between 1 and 1.6 for hard materials and above 1.6 for softer ones. Hence SSA belongs to softer material category.

The elastic stiffness constant $\left(C_{11}\right)$ for different loads is calculated using wooster's empirical formula,

$$
C_{11}=\left(H_{v}\right)^{7 / 4}(\mathrm{GPa}) .
$$

Graph between load $P$ and stiffness constant $C_{11}$ shown in Figure 7 gives an idea about tightness of bonding between neighboring atoms. It also determines the intensity of the fracture stress under the uniform loading shown in Figure 8 and brittleness index $B i$ shown in Figure 9 and the yield strength $\sigma_{y}$ shown in Figure 10. The calculated mechanical parameter values of SSA are given in Table 3. It is evident from Table 3 that the parameter values are increased due to increase in load but decreased Brittle index.

\subsection{FT-Raman Spectral Analysis}

The FT-Raman spectrum of the SSA was recorded on a BRUKER RFS 27 FT-Raman spectrometer equipped with an FRA-106 FT-Raman accessory in the region $4000-500 \mathrm{~cm}^{-1}$ using the $1064 \mathrm{~nm}$ line of Nd: YAG laser for excitation operating at $200 \mathrm{~mW}$ power with a resolution of $1 \mathrm{~cm}^{-1}$. The FT-Raman spectrum shown in Figure 11 also confirms the functional group. The intensity of the peaks in the spectrum is due to more free exposure for different groups. The 


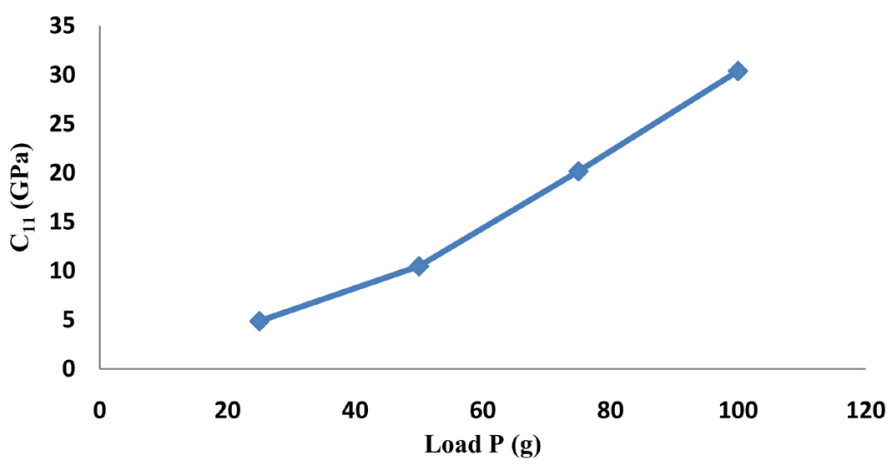

Figure 7. Graph between load $P$ and $C_{11}$.

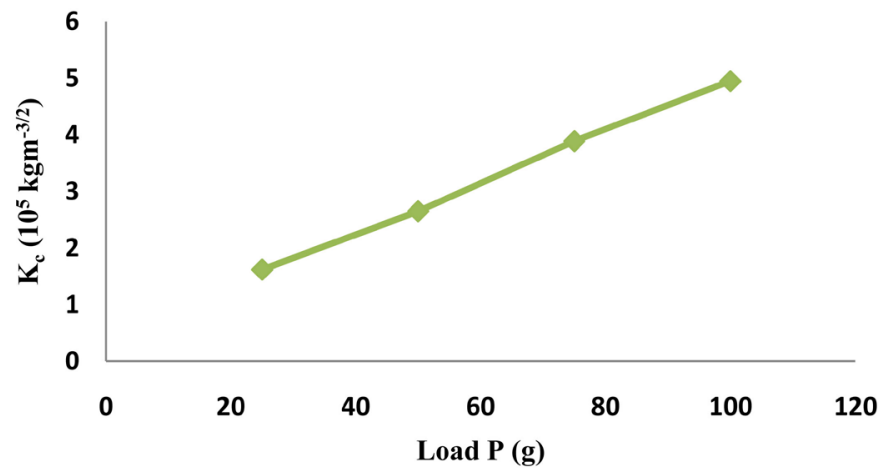

Figure 8. Graph between load $P$ and $C_{11}$.

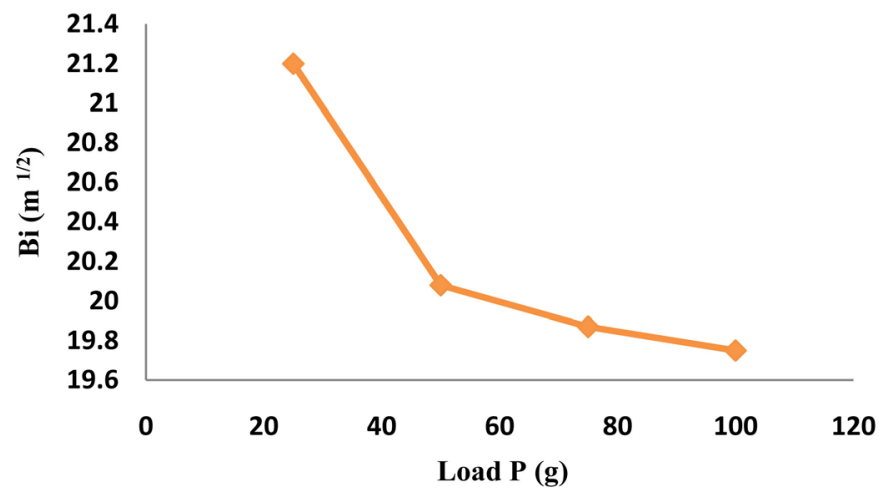

Figure 9. Graph between load $P$ and $B i$.

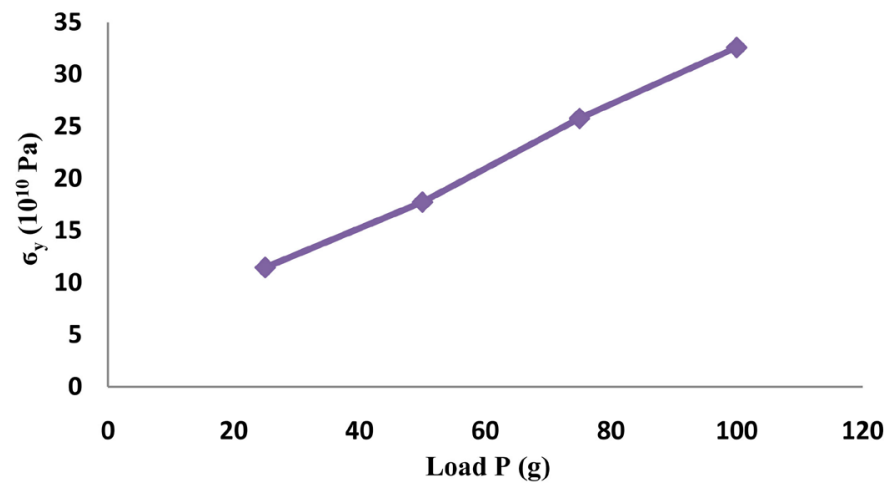

Figure 10. Graph between load $P$ and $\sigma_{r}$ 


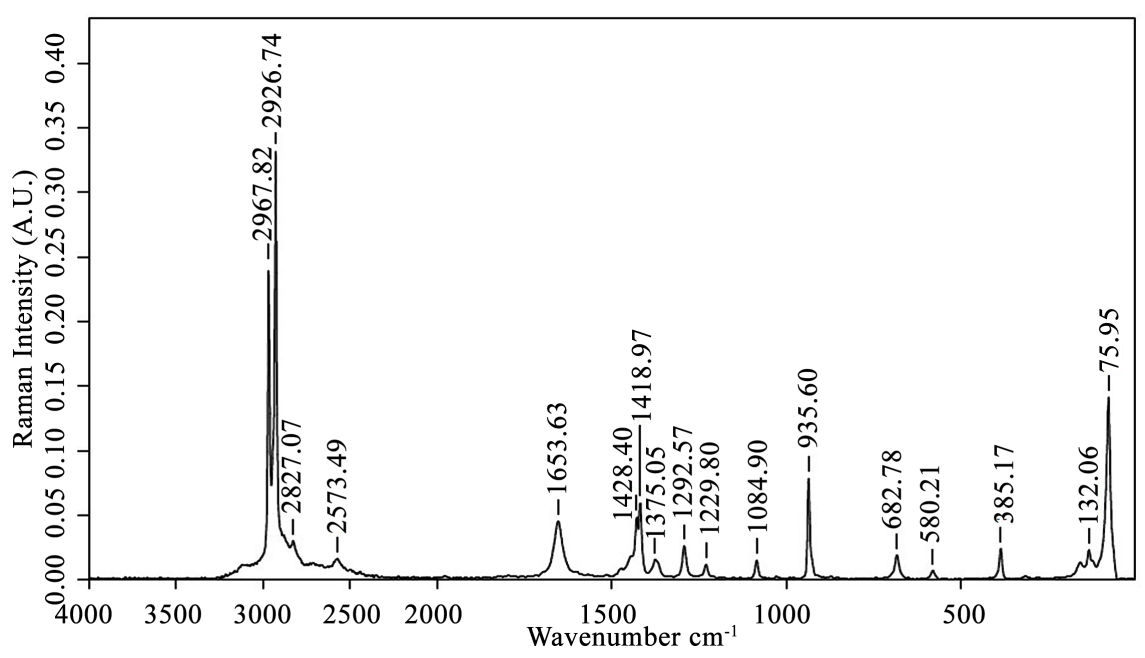

Figure 11. FT-Raman spectrum of SSA.

Table 3. Mechanical parameter values of SSA.

\begin{tabular}{ccccc}
\hline Mechanical parameters & $\begin{array}{c}\text { Load for } \\
\mathbf{2 5} \mathbf{~ g}\end{array}$ & $\begin{array}{c}\text { Load for } \\
\mathbf{5 0} \mathbf{~ g}\end{array}$ & $\begin{array}{c}\text { Load for } \\
\mathbf{7 5} \mathbf{~ g}\end{array}$ & $\begin{array}{c}\text { Load for } \\
\mathbf{1 0 0} \mathbf{~ g}\end{array}$ \\
\hline Hardness Number $H_{V}\left(\mathrm{Kg} / \mathrm{mm}^{2}\right)$ & 34.35 & 53.20 & 77.3 & 97.75 \\
Elastic stiffness constant $C_{11}(\mathrm{GPa})$ & 4.87 & 10.47 & 20.15 & 30.38 \\
Fracture toughness $K_{C}\left(10^{5} \mathrm{~kg} \cdot \mathrm{m}^{-3 / 2}\right)$ & 1.62 & 2.65 & 3.89 & 4.95 \\
Brittleness index $B i\left(\mathrm{~m}^{1 / 2}\right)$ & 21.20 & 20.08 & 19.87 & 19.75 \\
Yield Strength $\sigma_{y}\left(10^{10} \mathrm{~Pa}\right)$ & 11.45 & 17.73 & 25.77 & 32.58 \\
\hline
\end{tabular}

C-H symmetric stretching is observed at $2967.82 \mathrm{~cm}^{-1}$ as an intense sharp peak. The C-H stretching appears at $1418.97 \mathrm{~cm}^{-1}$ is due to the skeletal vibration. The $\mathrm{C}$-C stretching mode occurs at $1292.57 \mathrm{~cm}^{-1}$. The peak at $936 \mathrm{~cm}^{-1}$ illustrates the out of plane bending modes of $\mathrm{C}-\mathrm{H}$ bond.

\subsection{Nonlinear Optical Studies}

The nonlinear optical property of the grown SSA crystal is studied using Kurtz second harmonic generation (SHG) test. The crystal with reference to potassium dihydrogen orthophosphate (KDP) was carried out using Kurtz powder technique developed by Kurtz and Perry. The crystal was ground to homogeneous powder and tightly packed in a micro capillary tube and mounted in the path of the Q-switched Nd: YAG laser beam emitting $1064 \mathrm{~nm}, 15 \mathrm{~ns}$ pulse width with a repetition rate of $10 \mathrm{~Hz}$ and $7 \mathrm{~mJ}$ power [21]. The generated SHG signal at 532 $\mathrm{nm}$ is separated from the fundamental frequency using an IR separator. Further the emission of green light confirms the second harmonic generation on serine succinate crystal. The SHG efficiency of SSA material was found to be five times higher than that of standard potassium dihydrogen orthophosphate (KDP).

\subsection{Thermal Studies}

Thermal behaviour of the crystal was assessed by thermo gravimetric analysis 
(TGA), differential thermal analysis (DTA) and differential scanning calorimetry (DSC) using the instrument NETZSEH-STA 449 F3 GUPITER. The TGA was carried out in nitrogen atmosphere at a heating rate of $20^{\circ} \mathrm{C}$ per minute in the temperature range of $0^{\circ} \mathrm{C}$ to $350^{\circ} \mathrm{C}$. Figures 12-14 illustrates TG-DTG, TG-DSC and DSC curves for the grown SSA sample.

The curve shows a sharp weight loss at $190^{\circ} \mathrm{C}$ without any intermediate stages, which is assigned as melting point of the crystal [22]. There is no weight loss below $190^{\circ} \mathrm{C}$, illustrating the absence of absorbed water in the crystal.

Hence, we can conclude that there is no change in the melting point of the serine due to the addition of succinic acid. From the DSC trace, the endothermic peak observed at $190^{\circ} \mathrm{C}$ may be attributed to decomposition of succinic acid [23].

\subsection{SEM Analysis}

The SEM micrograph of SSA is shown in Figure 15. The photograph clearly reveals the step like growth pattern on the surface of the growth crystal and also

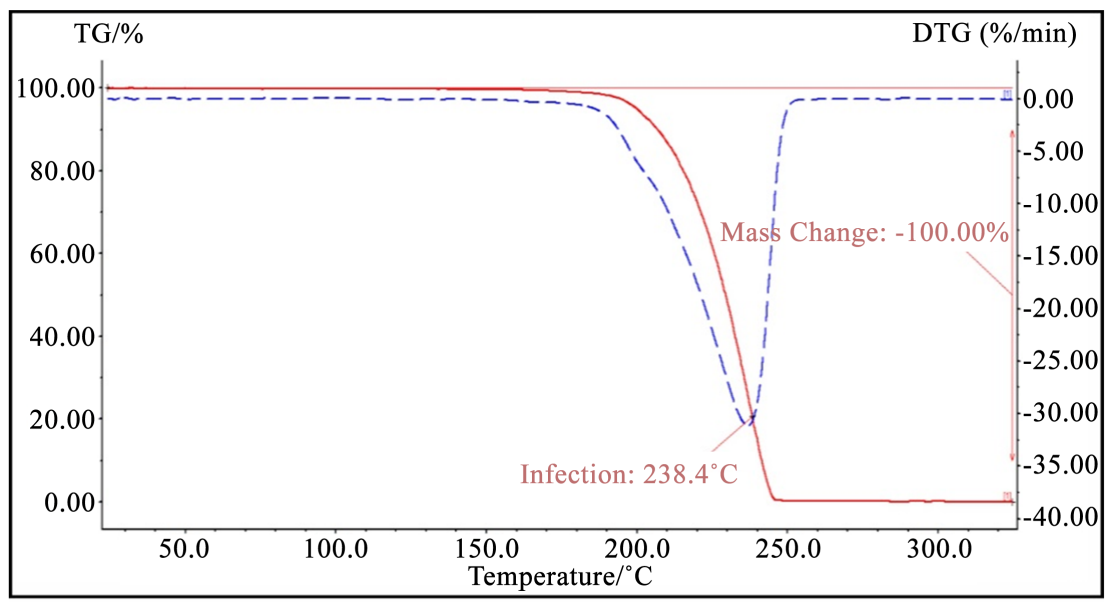

Figure 12. TG-DTG spectrum of SSA.

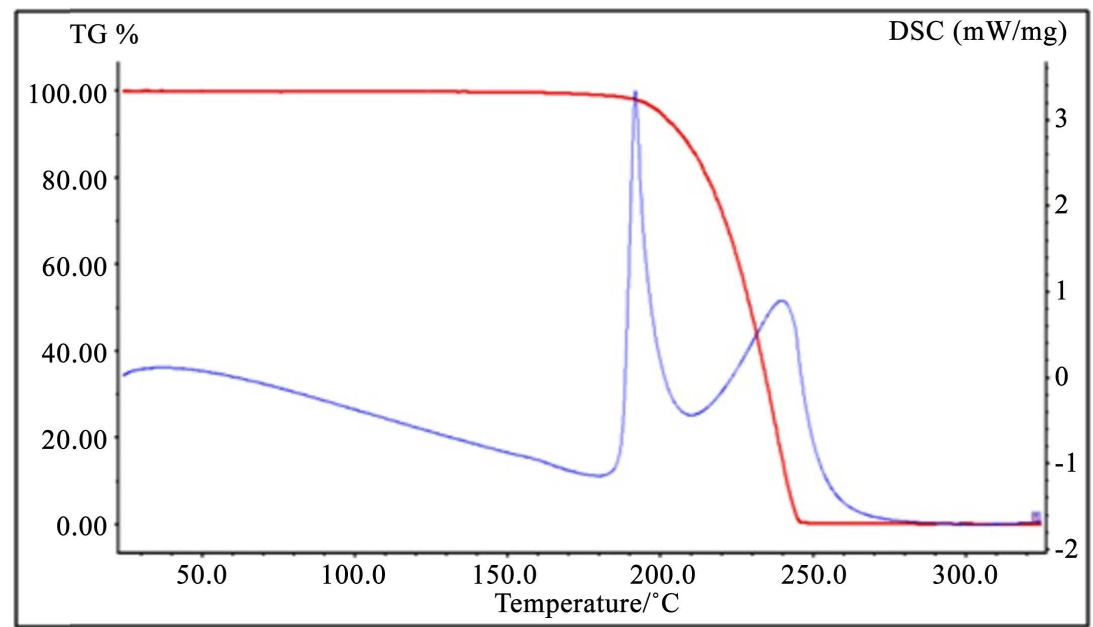

Figure 13. TGA-DSC spectrum of SSA. 


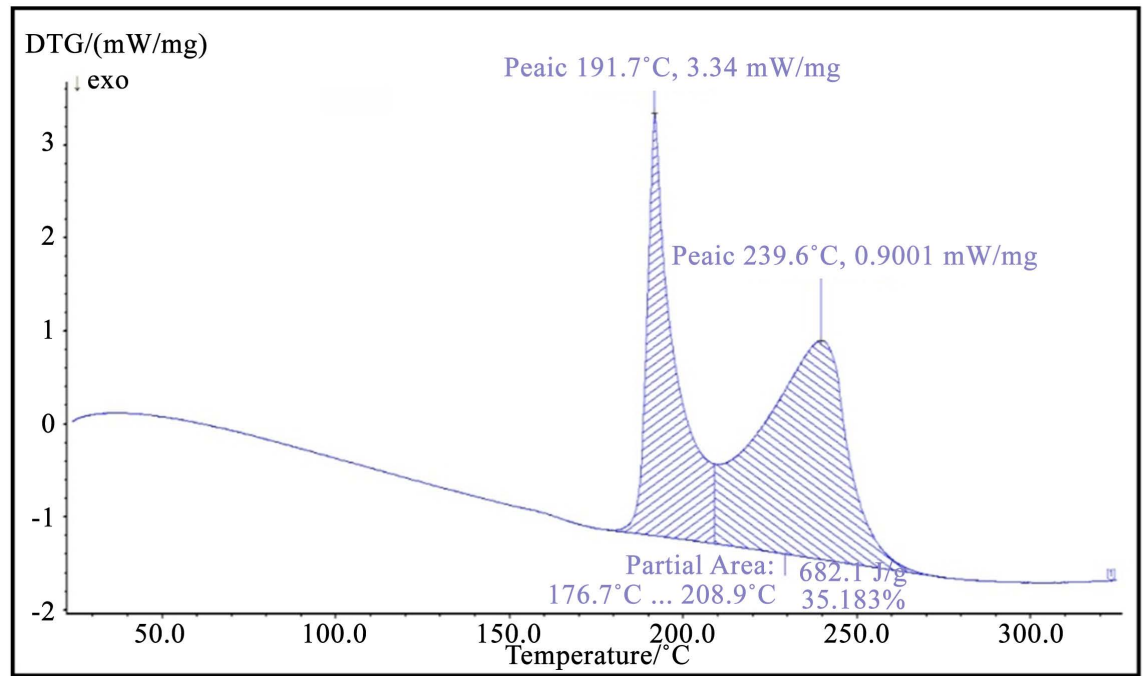

Figure 14. DSC spectrum of SSA.
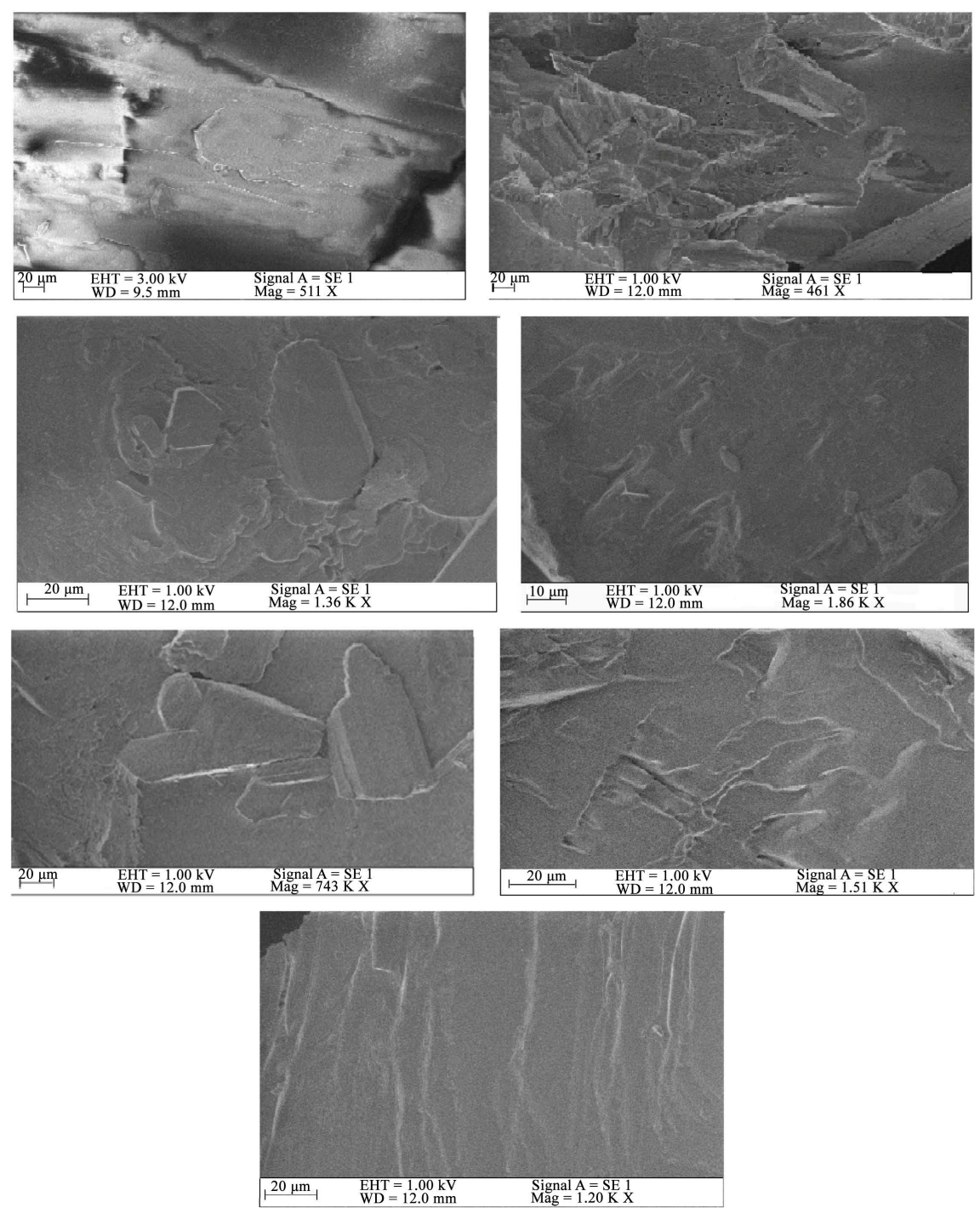

Figure 15. SEM analysis of SSA. 
the formation of few isolated islands. As the duration of irradiation increased, the morphology of the SSA crystallites changed markedly, with characteristic hexagonal shapes appearing after about $1 \mathrm{~min}$, longer durations resulted in the formation of distinct hexagonal. It is observed that the diameters are varied between 80 and $100 \mathrm{~nm}$, with lengths up to $500-600 \mathrm{~nm}$. The wall thickness of the SSA structure is about $40 \mathrm{~nm}$.

\section{Conclusion}

The nonlinear optical crystal of serine succinate is synthesized and grown from slow evaporation method at room temperature. The various characterization techniques have been employed to confirm the grown crystals such as single crystal XRD, FT-IR, UV-VIS-NIR, Fluorescence, mechanical studies, FT-Raman analysis, nonlinear optical property, thermal studies and SEM analysis. The single crystal X-ray diffraction data confirms that the grown crystal is monoclinic and the space group is $\mathrm{P}$. The lattice parameters are $\mathrm{a}=5.07 \AA, \mathrm{b}=8.81 \AA, \mathrm{c}=$ $5.50 \AA, \alpha=90.00^{\circ}, \beta=91.06^{\circ}, \gamma=90.00^{\circ}$ and Volume $=246 \AA^{3}$. The recorded FT-IR and FT-RAMAN spectrum of the grown crystal confirms the presence of functional groups in the compound. The UV-VIS-NIR transmission spectrum shows good transparency and the upper cut off wavelength is found to be 300 $\mathrm{nm}$. The fluorescence spectrum shows an emission peak at $465.87 \mathrm{~nm}$ and indicates that the crystal has blue emission of radiation. The micro hardness study reveals that the hardness increases with increases the load. Mechanical parameter values are also calculated for the sample. The SHG efficiency of the grown crystal is about five times that of potassium dihydrogen orthophosphate. The thermal behaviour of the crystal was confirmed by TGA analysis. Scanning electron microscopy study for the grown sample shows the surface quality of the crystals.

\section{Acknowledgements}

The authors thank the Indian Institute of Science-Bangalore for SHG measurement, Sophisticated Analytical Instruments Facility-Indian Institute of Technology, Chennai for the support in Single Crystal XRD data collection, FT-Raman, Thermal analysis and Archbishop Casimir Instrumentation Centre, St. Joseph College-Tiruchirappalli for FTIR, UV-VIS-NIR, Fluorescence, mechanical and SEM data analysis.

\section{Conflicts of Interest}

The authors declare no conflicts of interest regarding the publication of this paper.

\section{References}

[1] Marey, H.O., Warrn, L.F., Webb, M.S., Ebbers, C.A., Velsko, S.P., Kennedy, G.C. and Catella, G.C. (1992) Second-Harmonic Generation in Zinc Tris(Thiourea) Sul- 
fate. Applied Optics, 31, 5051-5060. https://doi.org/10.1364/AO.31.005051

[2] Ruiz, B., Jazbinsek, M.P. and Günter, P. (2008) Crystal Growth of DAST. Crystal Growth and Design, 8, 4173-4184. https://doi.org/10.1021/cg8003432

[3] Prasad, P.N. and Williams, D.J. (1991) Introduction to Nonlinear Optical Effects in Organic Molecules and Polymers. John Willey\& Sons, New York.

[4] Marder, S.R., Sohn, J.E. and Stucky, G.D. (1991) Materials for Nonlinear Optics. American Chemical Society, Washington DC. https://doi.org/10.1021/bk-1991-0455

[5] Romaniello, P. and Lelj, F. (2004) Effects of Fluorine Atoms on the Optical Nonlinear Response of Stilbene Derivatives. Journal of Fluorine Chemistry, 125, 145-149. https://doi.org/10.1016/j.jfluchem.2003.10.002

[6] Ledoux, I., Badan, J., Zyss, J., Migus, A., Hulin, D., Etchepare, J., Grillon, G. and Antonetti, A. (1987) Generation of High-Peak-Power Tunable Infrared Femtosecond Pulses in an Organic Crystal: Application to Time Resolution of Weak Infrared Signals. Journal of Optical Society of America, 4, 987-997. https://doi.org/10.1364/JOSAB.4.000987

[7] Sharada, G., Prabhu, P. and Mohan Rao. (2000) Growth and Characterisation of a New Promising NLO Mixed Borate Crystal. Journal of Optics, 29, 193-197.

[8] Kumar, R.M., Babu, D.R., Jayaraman, D., Jayavel, R. and Kitamura, K. (2005) Crystal Growth, Structure and Characterization of a New Semiorganic Nonlinear Optical Material- $\beta$-Alanine Zinc Chloride. Journal of Crystal Growth, 275, 1935-1939. https://doi.org/10.1016/j.jcrysgro.2004.11.260

[9] Monaco, S.B., Davis, L.E., Velsko, S.P., Wang, F.T., Eimerl, D. and Zalkin, A. (1987) Synthesis and Characterization of Chemical Analogs of L-Arginine Phosphate. Journal of Crystal Growth, 85, 252-256. https://doi.org/10.1016/0022-0248(87)90231-4

[10] Pal, T. and Kar, T. (2002) Single Crystal Growth and Characterization of the Nonlinear Optical Crystal L-Arginine Hydrofluoride. Journal of Crystal Growth, 234, 267-271. https://doi.org/10.1016/S0022-0248(01)01662-1

[11] Sathyalakshmi, R., Kannan, V., Bairava Ganesh, R. and Ramasamy, P. (2007) The Growth of L-Glutamic acid Hydrochloride Crystals. Crystal Research Technology, 42, 78-83. https://doi.org/10.1002/crat.200610775

[12] Koiev, T., Stamboliyska, B. and Yancheva, D. (2006) Spectral and Structural Study of Two Acceptor-Substituted Pyridinium-Betaines of Squaric Acid: Promising Chromophores for Nonlinear Optical Applications. Chemical Physics, 324, 489-496. https://doi.org/10.1016/j.chemphys.2005.11.014

[13] Meng, F.Q., Lu, M.K. Chen, J., Zhang, S.J. and Zeng, H. (1997) Characterization of Linear and Nonlinear Optical Properties of a New Single Crystal Urea-(d)tartaric Acid (UDT). Solid State Communication, 101, 925-928.

https://doi.org/10.1016/S0038-1098(96)00702-8

[14] Srinivasan, P., Kanagasekaran, T., Gopalakrishnan, R., Bhagavannarayana, G. and Ramasamy, P. (2006) Studies on the Growth and Characterisation of L-Asparaginium Picrate (LASP): A Novel Nonlinear Optical Crystal. Crystal Growth and Design, 6, 1663-1670. https://doi.org/10.1021/cg060094+

[15] Kalsi, P.S. (1985) Spectroscopy of Organic Compounds. Wiley Eastern, New Delhi.

[16] Meyers, R.A. (2000) Interpretation of Infrared Spectra, a Practical Approach John Coates in Encyclopedia of Analytical Chemistry, 10815-10837.

[17] Jothi, L., Vasuki, G., Ramesh Babu, R., et al. (2014) Synthesis, Crystal Growth and Characterization of Organic NLO Material: 4-Bromo-4'-Hydroxybenzylidene Ani- 
line. Optik, 125, 2017-2021. https://doi.org/10.1016/j.ijleo.2013.07.170

[18] Onitsch, E.M. and Mikroscopia (1956) The Present Status of Testing the Hardness of Materials. Microscope, 95, 12-14.

[19] Hanneman, M. (1941) Metall. and Manch. 23, 135-140.

[20] Jothi, L., Ramesh Babu, R. and Ramamurthi, K. (2014) Synthesis, Growth and Characterization of Organic Nonlinear Optical Single Crystals of 4-Bromo-4'Methyl Benzylidene Aniline. Journal of Minerals and Materials Characterization and Engineering, 2, 308-318. https://doi.org/10.4236/jmmce.2014.24036

[21] Kurtz, S.K. and Perry, J.J. (1968) A Powder Technique for the Evaluation of Nonlinear Optical Materials. Journal of Applied Physics, 39, 3798. https://doi.org/10.1063/1.1656857

[22] Santhana Raghavan, P. and Ramasamy, P. (2000) Crystal Growth Processes and Methods. K.R.U. Publication, Kumbakonam.

[23] Silverstein, R.M. and Webster, F.X. (1998) Spectrometric Identification of Organic Compounds. 6th Edition, John Wiley Eastern Sons Inc., New York. 